\title{
Original
}

\section{Sterilization Effect of Wet Oxygen Plasma in the Bubbling Method}

\author{
KAORU TAMAZAWA ${ }^{1 *}$, HIDEHARU SHINTANI ${ }^{2}$, YOSHINORI TAMAZAWA $^{3}$, \\ AND HIDETOSHI SHIMAUCHI \\ 'Department of Periodontology and Endodontology, Tohoku University Graduate School of Dentistry, \\ 4-1, Seiryo-machi, Aoba-ku, Sendai, Miyagi 980-8575, Japan \\ ${ }^{2}$ Chuo University, Department of Science, 1-13-27 Kasuga, Bunkyo-ku, Tokyo 112-8551, Japan \\ ${ }^{3}$ Clinical Division of Infection Control, Tohoku University Hospital, \\ 4-1, Seiryo-machi, Aoba-ku, Sendai, Miyagi 980-8575, Japan
}

Received 16 December, 2014/Accepted 9 June, 2015

\begin{abstract}
A new low-temperature sterilization method to replace the ethylene oxide gas sterilization is needed. Strong bactericidal effects of $\mathrm{OH}$ and $\mathrm{O}_{2} \mathrm{H}$ radicals are well known. The purpose of this study was to evaluate the sterilization effect of wet oxygen $\left(" \mathrm{O}_{2}+\mathrm{H}_{2} \mathrm{O}\right.$ ") plasma in the bubbling method, confirming the effect of humidity. Sterility assurance was confirmed by using a biological indicator (Geobacillus stearothermophilus ATCC7953, Namsa, USA). One hundred and eight samples $\left(10^{5}\right.$ spores/carrier) were divided into three groups of 36 in each for treatment with a different type of gas $\left(\mathrm{O}_{2}, \mathrm{O}_{2}+\mathrm{H}_{2} \mathrm{O}\right.$, Air $\left.+\mathrm{H}_{2} \mathrm{O}\right)$. Plasma processing was conducted using a plasma ashing apparatus (13.56 MHz, PACK- $3^{\circledast}$, Y. A. C., Japan) under various gas pressures $(13,25,50$ $\mathrm{Pa})$ and gas flows $(50,100,200 \mathrm{sccm})$. Fixed plasma treatment parameters were power at 150 $\mathrm{W}$, temperature of $60^{\circ} \mathrm{C}$, treatment time of $10 \mathrm{~min}$. The samples after treatment were incubated in trypticase soy broth at $58^{\circ} \mathrm{C}$ for $72 \mathrm{~h}$. The negative culture rate in the " $\mathrm{O}_{2}+\mathrm{H}_{2} \mathrm{O}$ " group was significantly (Mantel-Haenszel procedure, $\mathrm{p}<0.001$ ) higher than in the other gas groups. It is suggested that the significant sterilization effect of the " $\mathrm{O}_{2}+\mathrm{H}_{2} \mathrm{O}$ " group depends on the bubbling method which is the method of introducing vapor into the chamber. The bubbling method seems able to generate $\mathrm{OH}$ and $\mathrm{O}_{2} \mathrm{H}$ radicals in a stable way.
\end{abstract}

Key words : Oxygen gas plasma / Water / Sterilization / Microorganism.

\section{INTRODUCTION}

Most of the medical and surgical devices used in healthcare facilities are made of materials that are heat stable, and therefore undergo heat, primarily steam sterilization. On the other hand, for moisture or heatsensitive medical devices, ethylene oxide (EO) gas sterilization has been used. However, institutions presently tend to refrain from using EO gas sterilization because it leaves a very hazardous residue. At the same time, special or valuable devices with sharp blades or delicate or complicated structures are sterilized by EO gas even now, even if the device material is stainless

*Corresponding author. Tel: +81-22-717-8334, Fax: +81-22717-8339, E-mail : tamazawa(a)dent.tohoku.ac.jp steel which is resistant to heat or moisture. Therefore, a new low-temperature sterilization method to replace EO gas sterilization is urgently needed in medical practice today.

As a consequence, many studies have been done with the aim of developing non-toxic low-temperature sterilization methods, including those applying lowtemperature plasma technology. Many studies have shown that various gases such as argon, oxygen, nitrogen or hydrogen peroxide have sporicidal activity (Griffiths 1993; Crow and Smith, 1995; Feldman et al., 1997; Soloshenko et al., 2000, Montie et al., 2000; Lerouge et al., 2000a; Lerouge et al., 2000b; Moisan et al., 2001; Tamazawa, 2004; Stoffels et. al., 2004; Shintani et al., 2007). In addition, water vapor was shown to be an effective processing gas (Nagatsu et 
al., 2005; Hayashi et al., 2006; Hayashi et al., 2008; Oh et al., 2009; Fumagalli et al., 2012). Low-temperature gas plasmas are generated when certain gases are stimulated under a vacuum or an atmospheric pressure with radio-frequency or microwave energy. Among them, atmosphere pressure plasma (APP) has attracted attention because APP has a great advantage of not requiring a vacuum pump in its production. However, under atmospheric pressure, ozone would be inevitably generated. We have regarded ozone as an unsuitable gas for medical sterilization, due to the argument of whether ozone is a toxic gas. In order to produce safe plasma using gas containing oxygen, it is necessary to reduce the oxygen pressure and flow rate to a level that will not generate ozone (Tabata, 1998).

The present study was therefore performed by using a plasma ashing apparatus capable of generating oxygen radicals in the etching without generating ozone.

Strong bactericidal effects of $\mathrm{OH}$ and $\mathrm{O}_{2} \mathrm{H}$ radicals are well known (Jacobs et al., 2001; Soloshenko et al., 2002). In the low-temperature region, $\mathrm{OH}$ radicals are faster than $\mathrm{O}$ radicals in the rate of the oxidation for organic materials (Miyoshi, 2009). Also, $\mathrm{OH}$ radicals oxidize organic matter indiscriminately yet at a high speed; on the other hand, ozone oxidizes unsaturated compounds selectively.

The purpose of this study was to evaluate the sterilization efficacy of the $\mathrm{O}_{2}$ radicals and $\mathrm{OH}$ radicals generated by the wet $\mathrm{O}_{2}$ bubbled in water. Furthermore, we examined the cold spots in the apparatus chamber using a custom-made quartz rack in order to develop a new low-temperature sterilization method suitable for the next generation.

\section{MATERIALS AND METHODS}

\section{Sterilization effect of the three types of plasma}

\section{treatment on Geobacillus stearothermophilus eval- uated by the broth-culture method}

Plasma treatment was conducted using a plasma ashing apparatus (Fig.1, Table 1, PACK- $3^{\circledR}$, Y. A. C., Co. Ltd., Tokyo, Japan) for the semiconductor. Sterility assurance was confirmed by using a biological indicator (BI). The carriers for inoculating $\mathrm{BI}$ were custom-made. The carrier was a disc of stainless steel with a diameter of $12 \mathrm{~mm}$ and a recess depth of $1 \mathrm{~mm}$ within a diameter of $10 \mathrm{~mm}$ so that a spore-suspension could be inoculated uniformly (Fig.2 (a)). The BI (Geobacillus stearothermophilus ATCC 7953, $2.2 \times 10^{6}$ spores/0.1 $\mathrm{mL}$, Namsa Co. Ltd., USA) was inoculated $(10 \mu \mathrm{L})$ into the carrier $\left(10^{5}\right.$ spores per carrier), and dried in a desiccator at $37^{\circ} \mathrm{C}$ for 30 min or more.

Sterilization validation was conducted by using three types of gas plasma: $\mathrm{O}_{2}$ gas, " $\mathrm{O}_{2}+\mathrm{H}_{2} \mathrm{O}$ " gas and "Air+ $\mathrm{H}_{2} \mathrm{O}$ " gases. One hundred and eight $\mathrm{Bl}$-samples were used in total, and they were divided into three groups of

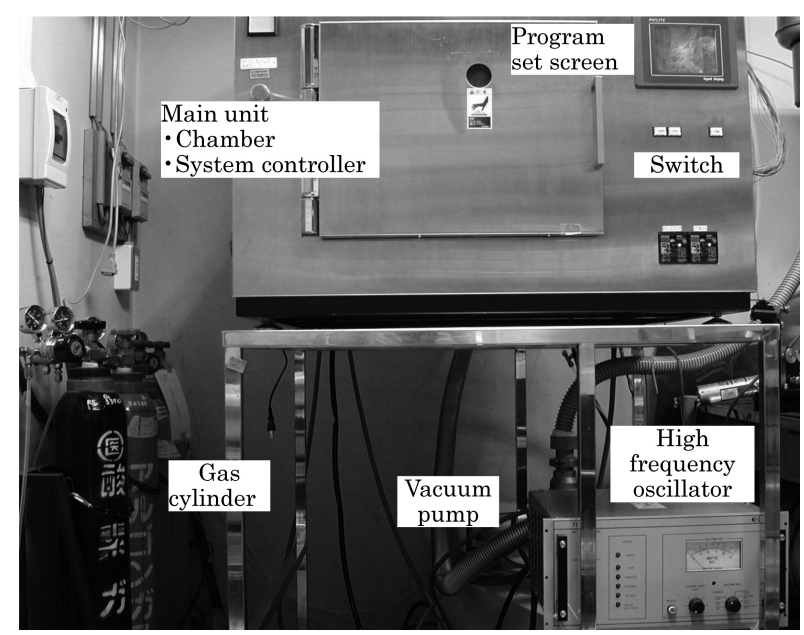

FIG. 1. Desktop plasma ashing system $\left(P A C K-3^{\circledR}, 13.56\right.$ MHz, Y. A. C. Co., Ltd., Tokyo, Japan).

TABLE 1. The specifications of the plasma apparatus.

\begin{tabular}{cl}
\hline & \multicolumn{1}{c}{ Main unit specification } \\
\hline RF generator & Frequency: $13.56 \mathrm{MHz}$, Maximum power: $500 \mathrm{~W}$ \\
Service power & AC 200 V, Single phase $50 \mathrm{~Hz}$, Electric capacity $1.5 \mathrm{~kW}$ \\
Process system & Electrode: Parallel type \\
Chamber & $300 \mathrm{~mm}(\phi) \times 400 \mathrm{~mm}(\mathrm{~L})$, made of the quartz \\
Gas lines and & $(1) 2$ lines for process gas: mass flow \\
control method & $(2) 1$ line for $\mathrm{N}$ purge: metering valve \\
Matching unit & This is unit minimizes a reflected wave power against load fluctuations \\
(Auto, Manual) & due to a change of vacuum degree and gas flow rate \\
Processing condition & Program set screen controlled by the microcomputer \\
Vacuuming system & Dry vacuum pump: slow purge/slow vacuum system \\
\hline
\end{tabular}




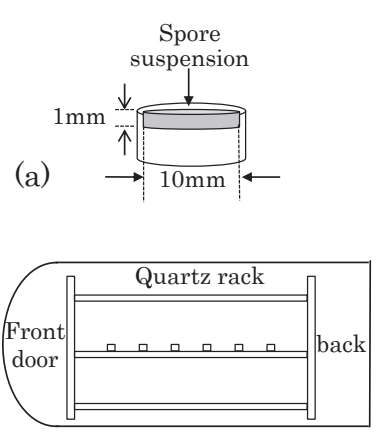

(b)

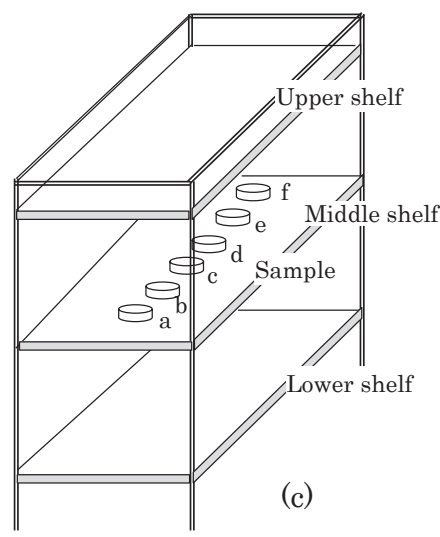

FIG. 2. Bl-sample (a), plasma chamber (b) and sample position (c).

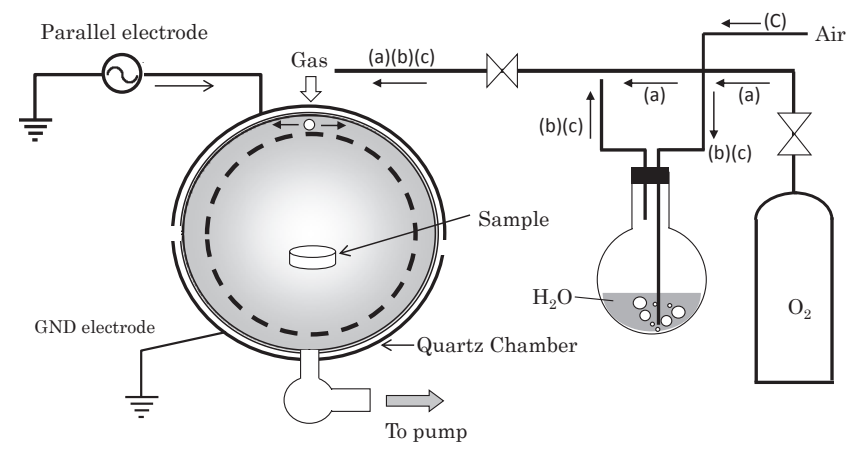

FIG. 3. Methods of introducing the processing gas into the chamber (a) $\mathrm{O}_{2}$ gas, (b) $\mathrm{O}_{2}+\mathrm{H}_{2} \mathrm{O}$ " gas and (c) "Air $+\mathrm{H}_{2} \mathrm{O}$ " gas.

\section{Bls per each.}

" $\mathrm{O}_{2}$ plasma" was generated by introducing $\mathrm{O}_{2}$ directly from the oxygen cylinder into the apparatus chamber. Also, " $\mathrm{O}_{2}+\mathrm{H}_{2} \mathrm{O}$ plasma" was generated by introducing wet $\mathrm{O}_{2}$ passed through bubbling water stored in the container (this method is referred to as the bubbling method hereafter). In the same way, "Air $+\mathrm{H}_{2} \mathrm{O}$ plasma" was generated by introducing wet air (Fig.3).

Six Bl-samples were placed at a time side by side at about $5 \mathrm{~cm}$ intervals in the middle shelf of the custom made quartz rack (Fig.2 (b) and 2 (c)), and followed by plasma treatment. Fixed parameters of the plasma treatment were power at $150 \mathrm{~W}$, temperature of $60^{\circ} \mathrm{C}$, treatment time of $10 \mathrm{~min}$. On the other hand, the gas pressure was varied at $13,25,50 \mathrm{~Pa}$ (Pascal), and the flow rate was 50, 100, $200 \mathrm{sccm}$ (standard cubic centimeter per min). That is to say, plasma treatment was conducted under six conditions (I: $13 \mathrm{~Pa}, 50$ sccm; II: $13 \mathrm{~Pa}, 100$ sccm; III: $25 \mathrm{~Pa}, 50$ sccm; IV: 25 $\mathrm{Pa}, 200 \mathrm{sccm}$; V: $50 \mathrm{~Pa}, 50 \mathrm{sccm}$; VI: $50 \mathrm{~Pa}, 200$ sccm).

In addition, sterilization validation was also done to

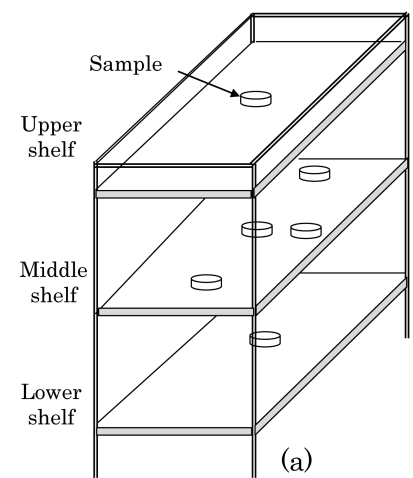

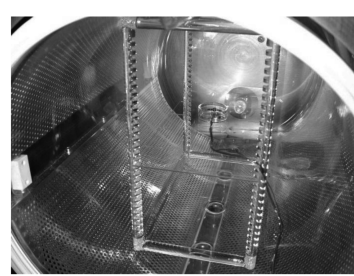

(b)
FIG. 4. Sample positions in the quartz rack (a) and apparatus chamber (b) in the cold spot measurement.

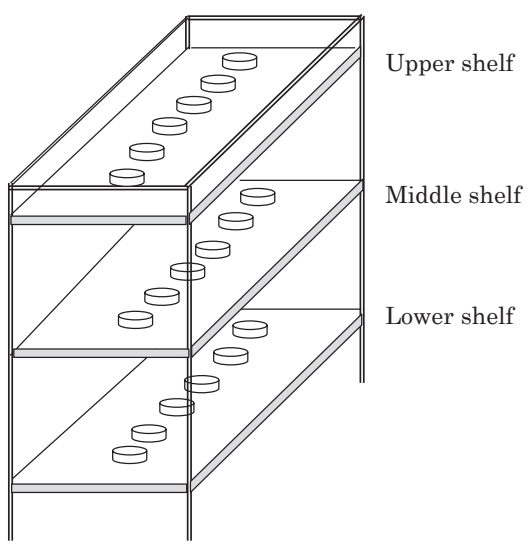

FIG. 5. Sample positions in the quartz rack during plasma treatment.

examine the effect of air pressure without plasma discharge. Twenty-eight $\mathrm{Bl}$-samples in the range from $10^{6}$ spores to $10^{3}$ spores per carrier were used in this experiment. These samples were treated with heating in the range of $60^{\circ} \mathrm{C}$ to $140^{\circ} \mathrm{C}$ under vacuum pressure or atmospheric pressure.

All the Bl-samples were retrieved aseptically immediately from the plasma apparatus after treatment. Retrieved $\mathrm{Bl}$-samples were cultivated in trypticase soy broth at $58^{\circ} \mathrm{C}$ for $72 \mathrm{~h}$ and the sterilization effect on the samples was evaluated by the presence or absence of turbidity of the broth.

\section{Measurement of the cold spots in the chamber and the sample temperature after plasma treatment}

In order to detect the cold spots in this apparatus chamber, six carriers with temperature indicators (Micron Co. Ltd., Tokyo, Japan) were placed inside. One was placed on the upper shelf, four on the middle and one on the lower shelf of the quartz rack (Fig.4), and they were treated without plasma discharge but with 5 min of heating at $100^{\circ} \mathrm{C}$. The carrier temperature 
was measured after treatment. Together with the six carriers, a carrier equipped with a thermocouple was placed on the middle shelf and the temperature was measured using a data logger (NR-1000, Keyence Corporation, Tokyo, Japan).

Furthermore, the temperature increase in the sample by plasma chemical reaction was measured. Eighteen carriers with temperature indicators were placed in the rack: six on the upper shelf, six on the middle and six on the lower shelf (Fig.5). They were then treated with $\mathrm{O}_{2}$ plasma at a gas pressure of $25 \mathrm{~Pa}$ and a gas flow of $50 \mathrm{sccm}$ at $60^{\circ} \mathrm{C}$ for $10 \mathrm{~min}$.

\section{RESULTS AND DISCUSSION}

\section{Sterilization effect of the three types of plasma treatment on Geobacillus stearothermophilus eval- uated by the broth-culture method}

The sterilization effect was evaluated by examining for the presence of the remaining viable cells after the three types of treatments. Concretely that was done by evaluating the turbidity of the cultured BI-sample. Table 2-1 and 2-2 showed the culture results of the three types of the plasma. First, statistical analysis was performed on the data in Table 2-1 among the treatment conditions and the positions of $\mathrm{Bl}$ for each type of plasma.

Among the treatment conditions, $" \mathrm{O}_{2}+\mathrm{H}_{2} \mathrm{O}$ " plasma showed no significant difference $(P=0.71$, Table 2-1-b), but in general showed negative-cultures in most of the treatment conditions. On the other hand, with $\mathrm{O}_{2}$ plasma and "Air $+\mathrm{H}_{2} \mathrm{O}$ "plasma, the sterilization effect was different among the treatment conditions. Namely, the conditions which showed more negative cultures and the conditions which showed fewer negative cultures could be clearly distinguished. In the results of the statistical analysis, $\mathrm{O}_{2}$ plasma showed a significant difference in the culture results among the six treatment conditions (Friedman test, $\mathrm{p}<0.01 \quad(\mathrm{P}=0.002)$, Table 2-1-a, ), but Air $+\mathrm{H}_{2} \mathrm{O}$ " plasma did not ( $\mathrm{P}=0.09$, Table $2-1-c)$. However, there was no significant difference in all three types of plasma regarding the positioning of $\mathrm{BI}$.

Following this, statistical analysis was performed using the data in Table 2-2 which was created without reference to the sample positions, in order to determine whether there is a difference in the sterilization effect among the three types of gas. As shown in Table 2-2, " $\mathrm{O}_{2}+\mathrm{H}_{2} \mathrm{O}$ " plasma had significantly (Mantel-Haenszel procedure, $\mathrm{p}<0.001$ ) higher values than $\mathrm{O}_{2}$ plasma or "Air $+\mathrm{H}_{2} \mathrm{O}$ " plasma. In other words, " $\mathrm{O}_{2}+\mathrm{H}_{2} \mathrm{O}$ " plasma showed the highest efficiency in the sterilization effect. Also, there was no significant difference in effects of "Air $+\mathrm{H}_{2} \mathrm{O}$ " plasma and those of $\mathrm{O}_{2}$ plasma.

The main mechanisms of spore destruction or deactivation by plasma discharge have been reported (Lerouge
TABLE 2-1-a. Culture results of $\mathrm{O}_{2}$ plasma treatment on Geobacillus stearothermophilus ATCC 7953

\begin{tabular}{|c|c|c|c|c|c|c|c|}
\hline & & \multicolumn{6}{|c|}{ Position N.S. $^{\text {N.S. }}$} \\
\hline & & a & $b$ & C & $d$ & e & $f$ \\
\hline \multirow{6}{*}{ 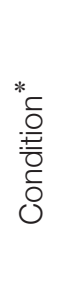 } & I & - & - & - & - & - & - \\
\hline & $\|$ & - & - & - & - & - & - \\
\hline & III & + & + & + & - & + & + \\
\hline & IV & - & - & - & - & - & - \\
\hline & V & + & - & + & - & + & + \\
\hline & VI & + & + & + & + & + & + \\
\hline
\end{tabular}

TABLE 2-1-b. Culture results of " $\mathrm{O}_{2}+\mathrm{H}_{2} \mathrm{O}$ " plasma treatment on Geobacillus stearothermophilus ATCC 7953

\begin{tabular}{|c|c|c|c|c|c|c|c|}
\hline & & \multicolumn{6}{|c|}{ Position N.S. $^{\text {N.S. }}$} \\
\hline & & a & $b$ & C & $d$ & e & $f$ \\
\hline \multirow{6}{*}{ 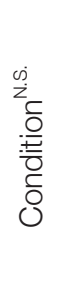 } & I & - & - & - & - & - & - \\
\hline & $\|$ & - & - & - & - & - & - \\
\hline & III & - & - & - & - & + & - \\
\hline & IV & - & - & - & - & - & - \\
\hline & V & - & + & - & - & - & - \\
\hline & VI & - & - & + & + & + & - \\
\hline
\end{tabular}

TABLE 2-1-c. Culture results of "Air $+\mathrm{H}_{2} \mathrm{O}$ " plasma treatment on Geobacillus stearothermophilus ATCC 7953

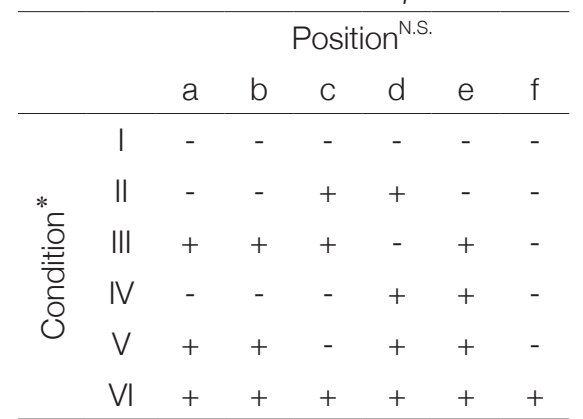

Position: refer to Fig.2 (b) and Fig.2 (c)

Condition I: $13 \mathrm{~Pa}, 50 \mathrm{sccm}$; Condition II: $13 \mathrm{~Pa}, 100$ sccm; Condition III: 25 Pa, 50 sccm; Condition IV: 25 Pa, 200 sccm; Condition V: 50 Pa, 50 sccm; Condition VI: 50 Pa, 200 sccm. *: significant, $\mathrm{p}<0.05$ (Friedman test)

N.S.: no significant, $p>0.05$

et al., 2000a; Lerouge et al., 2000b; Kim et al., 2006; Boudam et al., 2006). There are two main mechanisms: the etching by the atomic oxygen or oxygen radicals and VUV/UV emissions (Philip et al., 2002).

In this study, the main mechanism was the synergistic effect of etching and humidity as shown in Table 2-1 and 2-2. The reason is that the apparatus used in this study is a plasma asher. Etching by oxygen plasma is called ashing. The gas used is usually oxygen gas for 
TABLE 2-2. Number of negative cultures and positive cultures. Sterilization effect of three types of plasma on Geobacillus stearothermophilus ATCC 7953.

\begin{tabular}{|c|c|c|c|c|}
\hline \multirow{2}{*}{ Condition } & \multirow{2}{*}{$\begin{array}{l}\text { Culture } \\
\text { result }\end{array}$} & \multicolumn{3}{|c|}{ Plasma } \\
\hline & & $\mathrm{O}_{2}$ & $\mathrm{O}_{2}+\mathrm{H}_{2} \mathrm{O}$ & $\mathrm{Air}+\mathrm{H}_{2} \mathrm{O}$ \\
\hline \multirow{2}{*}{ I } & negative & 6 & 6 & 6 \\
\hline & positive & 0 & 0 & 0 \\
\hline \multirow{2}{*}{ П } & negative & 6 & 6 & 4 \\
\hline & positive & 0 & 0 & 2 \\
\hline \multirow{2}{*}{ III } & negative & 1 & 5 & 2 \\
\hline & positive & 5 & 1 & 4 \\
\hline \multirow{2}{*}{ IV } & negative & 6 & 6 & 4 \\
\hline & positive & 0 & 0 & 2 \\
\hline \multirow{2}{*}{ V } & negative & 2 & 5 & 2 \\
\hline & positive & 4 & 1 & 4 \\
\hline \multirow{3}{*}{$\mathrm{VI}$} & negative & 0 & 3 & 0 \\
\hline & positive & 6 & 3 & 6 \\
\hline & & \multicolumn{3}{|c|}{ 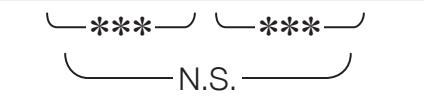 } \\
\hline
\end{tabular}

Position: refer to Fig.2 (b) and Fig.2 (c)

Condition l: $13 \mathrm{~Pa}, 50$ sccm; Condition II: $13 \mathrm{~Pa}, 100$ sccm; Condition III: $25 \mathrm{~Pa}, 50$ sccm; Condition IV: $25 \mathrm{~Pa}, 200$ sccm; Condition V: 50 Pa, 50 sccm; Condition VI: 50 Pa, 200 sccm. *** : significant, $\mathrm{p}<0.001$ (Mantel-Haenszel procedure)

N.S.: no significant, $p>0.05$

the plasma ashing process. If there is inorganic matter, it will turn into a residue known as ash. The byproducts of this process are mainly volatile carbon oxides and water vapor. These byproducts are pumped away with the vacuum pump within the plasma asher. In the above described process, when the inorganic material is replaced with microorganisms, ashing would be an ideal sterilization process.

The etching effect leads to the direct killing of spores by destruction of the inner membrane, thereby possibly causing damage to the germinant receptors located in the membrane without any damage to the DNA in the cores (Zhao et al., 2011a). The etching effect results in shrinkage of the microbial cell. It was reported that when the $\mathrm{O}_{2}$ gas mixture ratio increased, the more the shrinkage of spores was observed, and the sterilization effect increased (Akitsu et al., 2007; Shintani et al., 2010; Zhao et al., 2011b). As shown in Table 2-2, the "Air $+\mathrm{H}_{2} \mathrm{O}$ " plasma had a lower effect compared to " $\mathrm{O}_{2}+$ $\mathrm{H}_{2} \mathrm{O}$ " plasma. These results would be due to the low proportion of oxygen in the air.

As shown in Table 2-1 and 2-2, all the Bls treated in condition I under which the gas pressure was $13 \mathrm{~Pa}$ and the gas flow was $50 \mathrm{sccm}$ were successfully steri- lized in 10 min.

This result was probably due to the large amount of oxygen radicals generated. When varying the gas pressure, the emission intensities of the oxygen radicals at $777 \mathrm{~nm}$ and $\mathrm{OH}$ radicals at $306 \mathrm{~nm}$ were enhanced with a decrease in oxygen gas pressure (Hayashi et al., 2006). Generally, the reactivity of plasma increases when the gas pressure becomes lower, while the amount of reactant increases when it becomes higher. Thus, the optimal combination of gas pressure and gas flow rate, and the addition of other trace gases, should lead to a higher sterilization effect. Further research is needed to find the optimal processing combinations for low-temperature sterilization.

Strong bactericidal effects of $\mathrm{OH}$ and $\mathrm{O}_{2} \mathrm{H}$ radicals are well known. $\mathrm{H}_{2} \mathrm{O}$ was used because the excitation of the electron levels of water molecules would in turn lead to the increase in the generation rate for oxygen atoms and oxygen molecules, and would be expected to generate $\mathrm{OH}$ and $\mathrm{O}_{2} \mathrm{H}$ radicals synergistically (Lerouge et al., 2000b; Oh et al., 2009). Also, it has been known that $\mathrm{OH}$ radicals have the strongest oxidizing power and react with the cells in a chain reaction with lipids to damage the cell membrane. However, $\mathrm{OH}$ radicals are very short-lived, and it is difficult to generate them stably (Shintani et al., 2010).

In this study, $\mathrm{H}_{2} \mathrm{O}$ was used instead of hydrogen as the gas for generating $\mathrm{OH}$ radicals, because $\mathrm{H}_{2} \mathrm{O}$ is easy and safe to handle.

As shown in Table 2-2, the sterilization effect of " $\mathrm{O}_{2}+$ $\mathrm{H}_{2} \mathrm{O}$ " plasma was significantly higher than $\mathrm{O}_{2}$ plasma. This excellent effect of " $\mathrm{O}_{2}+\mathrm{H}_{2} \mathrm{O}$ " plasma might be due to the effect of the added $\mathrm{H}_{2} \mathrm{O}$. Also, "Air $+\mathrm{H}_{2} \mathrm{O}$ " plasma was not significantly different from $\mathrm{O}_{2}$ plasma in the sterilization effect. It is important that "Air $+\mathrm{H}_{2} \mathrm{O}$ " plasma had a sterilization effect equal to $\mathrm{O}_{2}$ plasma although air has a low content of oxygen. The $\mathrm{OH}$ and $\mathrm{O}_{2} \mathrm{H}$ radicals from wet air would have a contribution to the increase in the sterilization effect.

In addition, it is important that this excellent effect of wet $\mathrm{O}_{2}$ plasma might be due to the method of generating $\mathrm{OH}$ and $\mathrm{O}_{2} \mathrm{H}$ radicals. In the bubbling method, $\mathrm{O}_{2}$ is introduced as wet $\mathrm{O}_{2}$ that is integrated with $\mathrm{H}_{2} \mathrm{O}$. Therefore, $\mathrm{OH}$ and $\mathrm{O}_{2} \mathrm{H}$ radicals could be generated in a stable and sufficient quantity (Bruggeman et al., 2010; Takamura et al., 2014) without causing condensation, or, that is, without exceeding the saturated vapor pressure.

However, wet plasma that was generated in a method different from the bubbling method did not show a constantly high sterilization effect (unpublished data). In this other method, the water vapor produced by heating the water was installed through another line with oxygen into the chamber, followed by generation of 
TABLE 3. The effect of air pressure on Geobacillus stearothermophilus ATCC 7953

\begin{tabular}{cc|cccc}
\hline \multicolumn{2}{c|}{ Condition } & \multicolumn{4}{c}{$\begin{array}{c}\text { Rate of negative cultures to } \\
\text { total cultures }\end{array}$} \\
\hline $\begin{array}{c}\text { Air } \\
\text { pressure }\end{array}$ & $\begin{array}{c}\text { Chamber } \\
\text { temperature }\end{array}$ & $10^{6 *}$ & $10^{5 *}$ & $10^{4 *}$ & $10^{3 *}$ \\
\hline$<5 \mathrm{~Pa}$ & $60^{\circ} \mathrm{C}$ & $0 / 1$ & $0 / 1$ & $0 / 1$ & $0 / 1$ \\
$<5 \mathrm{~Pa}$ & $80^{\circ} \mathrm{C}$ & $0 / 1$ & $0 / 1$ & & \\
$<5 \mathrm{~Pa}$ & $100^{\circ} \mathrm{C}$ & $0 / 1$ & $0 / 1$ & $0 / 1$ & $0 / 1$ \\
$<5 \mathrm{~Pa}$ & $120^{\circ} \mathrm{C}$ & $0 / 1$ & $0 / 1$ & & \\
$<5 \mathrm{~Pa}$ & $140^{\circ} \mathrm{C}$ & $1 / 1$ & $1 / 1$ & $1 / 1$ & $1 / 1$ \\
$0.1 \mathrm{MPa}$ & $140^{\circ} \mathrm{C}$ & $0 / 3$ & $0 / 3$ & $0 / 3$ & $0 / 3$ \\
\hline
\end{tabular}

*: spores / carrier

Treatment time: $10 \mathrm{~min}$

the plasma (this method is referred to as the mixing method hereafter). The reason why the mixing method sometimes has a low sterilization effect is considered to be that condensation occurs in the chamber and injection line because the amount of water vapor exceeds the saturation vapor pressure. Therefore, $\mathrm{O}$ radicals and $\mathrm{O}_{2}$ radicals as well as $\mathrm{OH}$ radicals and $\mathrm{O}_{2} \mathrm{H}$ radicals would not be sufficiently generated.

Furthermore, the effect of the vacuum pressure $(<5$ $\mathrm{Pa}$ ) on $\mathrm{Bl}$-samples was examined as shown in Table 3. Negative cultures could not be obtained when BIsamples were heated from $60^{\circ} \mathrm{C}$ to $120^{\circ} \mathrm{C}$. Finally, negative cultures were obtained at $140^{\circ} \mathrm{C}$. However, under atmospheric pressure, negative cultures could not be obtained even when heated at $140^{\circ} \mathrm{C}$.

This result showed that bacterial spores were not always inactivated by vacuum pressure while vegetative bacteria were usually killed, and the spores used in this study had a heat resistance up to $140^{\circ} \mathrm{C}$. However, our plasma could inactivate these resistant spores at $60^{\circ} \mathrm{C}$ as shown in Table 2-1 and 2-2. It should be noted that the plasma has an outstanding microbial effect.

\section{Measurement of the cold spots in the chamber and the sample temperature after plasma treatment}

When the chamber was heated at $100^{\circ} \mathrm{C}$ for $5 \mathrm{~min}$ without plasma discharge, the temperature of the carrier was $85.6^{\circ} \mathrm{C}$ (Table 4) as measured by a thermocouple in the central position of the middle shelf (Fig.4). The reason for this temperature difference is that the built-in thermocouple to control the temperature of the chamber is located in the upper area of the chamber. That is, it is positioned away from the carrier. Moreover the temperatures of the samples measured by the temperature indicators ranged from $77^{\circ} \mathrm{C}$ to $104^{\circ} \mathrm{C}$. Among these six samples, the spots showing a low-temperature zone, that is, cold spots, were in the center of the middle
TABLE 4. Temperature $\left({ }^{\circ} \mathrm{C}\right)$ of the sample position after treatment $^{1}$

\begin{tabular}{|c|c|c|c|c|}
\hline \multirow{2}{*}{ Shelf } & \multicolumn{4}{|c|}{ Sample position ${ }^{2}$} \\
\hline & Front & Center & Back & Right side \\
\hline Upper & & 88-93 & & \\
\hline Middle & $77-82$ & $\begin{array}{l}82-88 \\
85.6^{3} \\
\end{array}$ & $88-93$ & $99-104$ \\
\hline Lower & & 88-93 & & \\
\hline
\end{tabular}

TABLE 5. Sample temperature ( $\left.{ }^{\circ} \mathrm{C}\right)$ after plasma treatment ${ }^{1}$

\begin{tabular}{ccccccc}
\hline \multirow{2}{*}{ Shelf } & \multicolumn{6}{c}{ Sample position $^{2}$} \\
\cline { 2 - 7 } & $\mathrm{a}$ & $\mathrm{b}$ & $\mathrm{c}$ & $\mathrm{d}$ & $\mathrm{e}$ & $\mathrm{f}$ \\
\hline Upper & 60 & 60 & 65 & 65 & 65 & 60 \\
Middle & 65 & 65 & 65 & 71 & 65 & 71 \\
Lower & 65 & 65 & 65 & 65 & 65 & 65 \\
\hline
\end{tabular}

1: $60^{\circ} \mathrm{C}, \mathrm{O}_{2}$ plasma, $25 \mathrm{~Pa}, 50 \mathrm{sccm}, 150 \mathrm{~W}, 10 \mathrm{~min}$

2: Refer to Fig.5

shelf, in particular in front of the nearby door. On the other hand, the temperature of the sample on the right side was $99^{\circ} \mathrm{C}$ to $104^{\circ} \mathrm{C}$, and was near the set temperature. The reason for this was that the heater was installed in the side wall in the chamber. Based on this result, $\mathrm{Bl}$ samples used to examine the plasma sterilization effect were placed in the center of the middle shelf. The plasma chamber, ideally, should be heated to a uniform temperature as much as possible without having cold spots. To examine the cold spots precisely is important in terms of designing the sterilizer to attain confirmable sterilization effects.

Under $60^{\circ} \mathrm{C}$ conditions and the $\mathrm{O}_{2}$ plasma treatment for $10 \mathrm{~min}$, the temperature of the 18 samples ranged from $60^{\circ} \mathrm{C}$ to $71^{\circ} \mathrm{C}$ (Table 5). The chamber temperature was set to $60^{\circ} \mathrm{C}$, but sample temperature after $10 \mathrm{~min}$ treatment became $71^{\circ} \mathrm{C}$, indicating an $11^{\circ} \mathrm{C}$ increase.

This increased temperature may cause side effects such as discoloration or deterioration of instruments after sterilization. It was considered that the influence of the material is presumably small.

In conclusion, the wet $\mathrm{O}_{2}$ plasma was shown to exhibit a significantly higher sterilizing effect than $\mathrm{O}_{2}$ plasma. High bactericidal effects will depend on the stable generation of sufficient radicals. In the bubbling method, room temperature vapor is combined with $\mathrm{O}_{2}$ and introduced into the chamber, without causing condensation. 


\section{REFERENCES}

Akitsu, T., Ohkawa, H., Tsuji, M., Kimura, H., and Kogoma, M. (2005) Plasma sterilization using glow discharge at atmospheric pressure. Surf \& Coat Technology, 193, 29-34.

Boudam, M. K., Moisan, M., Saoudi, B., Popovici, C., Gheradi, N., and Massines, F. (2006). Bacterial spore inactivation by atmospheric-pressure plasmas in the presence or absence of UV photons as obtained with the same gas mixture. J. Phys. D: Appl. Phys., 39, 3494.

Bruggeman, P., Iza, F., Lauwers, D., and Gonzalvo, Y. A. (2010) Mass spectrometry study of positive and negative ions in a capacitively coupled atmospheric pressure RF excited glow discharge in He-water mixtures. J. Phys. D: Appl. Phys., 43, 012003.

Crow, S., and Smith, J. H. 3rd. (1995) Gas plasma sterilization-application of space-age technology. Infect. Control Hosp. Epidemiol., 16, 483-487.

Feldman, L. A., and Hui, H. K. (1997) Compatibility of medical devices and materials with low-temperature hydrogen gas plasma. Medical, Device, Diagnostic, Industry, 19, 57-62.

Fumagalli, F., Kylián, O., Amato, L., Hanuš, J., and Rossi, F. (2012) Low-pressure water vapour plasma treatment of surfaces for biomolecules decontamination. J. Phys. D: Appl. Phys., $45,1-9$.

Griffiths, N. (1993) Low-temperature sterilization using gas plasmas. Med. Device Technol., 4, 37-40.

Hayashi, N., Guan, W., Tsutsui, S., Tomari, T., and Hanada, Y. (2006) Sterilization medical equipments using radicals produced by oxygen/water vapor RF plasma. Jpn. J. Appl. Phys., 45, 8358-8363.

Hayashi, N., Tsutsui, S., Tomari, T., and Guan, W. (2008) Sterilization of medical equipment using oxygen radicals produced by water vapor RF plasma. IEEE Trans. Plasma Sci., 36, 1302-1303.

Jacobs, P. T., and Lin, S. M. (2001) Sterilization processes utilizing low-temperature plasmas. In Disinfection, Sterilization and Preservation. (Block, SS., ed), pp.747-765. Lippincott Williams \& Wilkins, New York.

Kim, S., and Kim, J. (2006) Decomposition of biological macromolecules by plasma generated with helium and oxygen. J. Microbiol-SEOUL, 44, 466-471.

Kylián, O., Sasaki, T., and Rossia, F. (2006) Plasma sterilization of Geobacillus Stearothermophilus by $\mathrm{O}_{2}: \mathrm{N}_{2}$ RF inductively coupled plasma. European Commission, Joint Research Centre Eur. Phys. J. Appl. Phys., 34, 139-142.

Lerouge, S., Wertheimer, M. R., Marchand, R., Tabrizian, M., and Yahia, L. (2000a) Effect of gas composition on spore mortality and etching during low-pressure plasma sterilization. J. Biomed. Mater .Res., 51, 128-135.

Lerouge, S., Fozza, AC., Wertheimer, MR., Marchand, R., and Yahia, L. (2000b) Sterilization by low-pressure plasma: the role of vacuum-ultraviolet radiation. Plasmas and Polymers, 5, 31-46.

Miyoshi, A. (2009) First-principle approach to combustion chemistry. J. Fuel Soc. Jpn., 51, 175-181.

Moisan, M., Barbeau, J., Moreau, S., Pelletier, J., Tabrizian, M., and Yahia, L. H. (2001) Low-temperature sterilization using gas plasmas: a review of the experiments and an analysis of the inactivation mechanisms. Int. J. Pharm.,
226, 1-21.

Montie, T. C., Kelly-Wintenberg, K., and Roth, J. R. (2000) An overview of research using the one atmosphere uniform glow discharge plasma (OAUGDP) for sterilization of surfaces and materials. IEEE Trans. Plasma Sci., 28, 41-50.

Nagatsu, M., Terashita, F., Nonaka, H., Xu, L., Nagata, T., and Koide, Y. (2005) Effect of oxygen radicals in low-pressure surface-wave plasma on sterilization. Appl. Phys. Lett., 86, 211502.

Oh, J. S., Kawamura, K., Pramanik, B. K., and Hatta, A. (2009) Investigation of water-vapor plasma excited by microwaves as ultraviolet light source. IEEE Trans. Plasma Sci., 37, 17-112.

Philip, N., Saoudi, B., Crevier, MC., Moisan, M., Barbeau, J., and Pelletier, J. (2002) The respective roles of UV photons and oxygen atoms in plasma sterilization at reduced gas pressure: the case of $\mathrm{N}_{2}-\mathrm{O}_{2}$ mixtures. IEEE Trans Plasma Sci., 30,1429-1436.

Rossi, F., Kylian, O., and Hasiwa, M. (2008) Mechanisms of sterilization and decontamination of surfaces by low-pressure plasma. In Advanced Plasma Technology (D'Agostino, R., Favia, P., Kawai, Y., Ikegami, H., Sato, N. and ArefiKhonsari, F., eds), pp.319-340, Wiley-VCH Verlag GmbH \& Co., Weinheim.

Shintani, H., Shimizu, N., Imanishi, Y., Sekiya, T., Tamazawa, K., Taniguchi, A., and Kido, N. (2007) Inactivation of microorganisms and endotoxins by low temperature nitrogen gas plasma exposure. Biocontrol Sci., 12, 131-143.

Shintani, H., Sakudo, A., Burke, P., and McDonnell, G. (2010) Gas plasma sterilization of microorganisms and mechanisms of action. Exp. Ther. Med., 1, 731-738.

Soloshenko, I. A., Tsiolko, V. V., Khomich, V. A., Shchedrin, A. I., Ryabtsev, A. V., Bazhenov, V. Y., and Mikhno, I. L. (2000) Sterilization of medical products in low-pressure glow discharges. Plasma Phys. Rep., 26, 792-800.

Soloshenko, I. A., Tsiolko, V. V., Khomich, V. A., Bazhenov, V. Y., Ryabtsev, A. V., Schedrin, A. I. and Mikhno, I. L. (2002) Features of sterilization using low-pressure DC-discharge hydrogen-peroxide plasma. IEEE Trans Plasma Sci., 30, 1440-1444.

Stoffels, E., Kieft, I. E., Sladek, R. E., van der Laan, E. P., and Slaaf, D. W. (2004) Gas plasma treatment: a new approach to surgery? Crit. Rev. Biomed. Eng., 32, 427-460.

Tabata, N. (1998) Ozone Generation and Generation Efficiency. J. Plasma Fusion Res., 74, 1119-1126.

Takamura, N., Wang, D., Akiyama, H., and Namihira, T. (2014) Generation of atmospheric-pressure mist plasma jet and its characteristics, J. Inst. Electrostat. Jpn. (in Japanese), 38, 22-27.

Tamazawa, K. (2004) Futures and problems on the plasma sterilization and future prospect of the new sterilization using low-temperature-plasma, Bokin Bobai (in Japanese), 32 , 13-30.

Zhao, Y., Ogino, A., and Nagatsu, M. (2011a) Mass spectrometric study on inactivation mechanism of spore-forming bacteria by low-pressure surface-wave excited oxygen plasma. Appl. Phys. Lett., 98, 191501.

Zhao, Y., Ogino, A., and Nagatsu, M. (2011b) Effects of $\mathrm{N}_{2}-\mathrm{O}_{2}$ gas mixture ratio on microorganism inactivation in low-pressure surface wave plasma. Jpn. Appl. Phys., 50, 1-5. 